\title{
Surgical and Non-surgical Follow-up Results of Ureteropelvic Junction Obstruction
}

\author{
Koc $\mathrm{ZP}^{1^{*}}$, Kara $\mathrm{AO}^{2}$, Bakal $\mathrm{U}^{3}$, Balcı $\mathrm{TA}^{4}$, Onur $\mathrm{MR}^{5}$ and Gurgoze $\mathrm{MK}^{2}$ \\ ${ }^{1}$ Department of Nuclear Medicine, Mersin University, Turkey \\ ${ }^{2}$ Department of Pediatric Nephrology, Firat University, Elazig, Turkey \\ ${ }^{3}$ Department of Pediatric Surgery, Firat University, Elazig, Turkey \\ ${ }^{4}$ Depatment of Nuclear Medicine, Fırat University, Elazig, Turkey \\ ${ }^{5}$ Department of Radiology, Medical Faculty, Hacettepe University, Ankara, Turkey
}

*Corresponding author: Zehra Pınar Koç, MD, Associate Professor, Department of Nuclear Medicine, Mersin University, 33343, Mersin, Turkey, Tel: +903242410000; E-mail: zehrapinarkoc@gmail.com

Received date: May 24, 2017; Accepted date: June 22, 2017; Published date: June 23, 2017

Copyright: @ 2017 Koc ZP, et al. This is an open-access article distributed under the terms of the Creative Commons Attribution License, which permits unrestricted use, distribution, and reproduction in any medium, provided the original author and source are credited.

\begin{abstract}
Purpose: We aimed to retrospectively compare the surgical and nonsurgical follow-up results of ureteropelvic junction obstruction without diuretic response.

Methods: Twenty nine pediatric patients (10 Female (F), 19 Male $(M)$; mean: $4.4 \pm 3.96$ years old, range: 0-15) without diuretic response were subject of this study. The diuretic renography, intravenous pyelography, voiding and ultrasonography were performed within one month and were compared with control ultrasonography and/or diuretic renography results in $7.4 \pm 6.7$ month follow-up.
\end{abstract}

Results: Among patients with surgical follow-up $11(100 \%)$ had recovery. In the follow-up group which consist of 18 patients 7 patients (39\%) had recovery, 5 had stable disease and 6 had additional pathologies (one ureter dilatation, infection in three, one worsening of diuretic response, one volume loss).

Conclusion: In patients without diuretic response in scintigraphy even without conclusive morphological results, surgery is more appropriate approach.

Keywords: Diuretic scintigraphy; Diuretic response; Ureteropelvic junction

\section{Introduction}

Ureteropelvic juntion (UPJ) obstruction is the most common cause of hydronephrosis in pediatric patients. Increased detection of antenatal hydronephrosis resulted in increasing number of patients with suspicion of UPJ obstruction. However, most of the patients with hydronephrosis in infantile period improve without any intervention and only follow-up in first year of life with imaging methods considered sufficient in the management of these patients. The clear indications of surgery are clinical symptoms including loss of the relative renal function of kidney less than $40 \%$ levels, complications including presence of renal calculi or hypertension.

Dynamic renal scintigraphy is an effective method in the identification of the patients with complete UPJ obstruction and incomplete obstruction. The most important information regarding the completeness of obstruction is the indication of the diuretic response. However, recent studies have demonstrated that the prolonged excretion function is not sufficient for determination of the completeness of the obstruction and hystopathologic results indicate the same finding [1]. Another study indicated that despite successful surgery the diuretic response may not necessarily improve [2]. There is a new parameter called 'tissue tracer transit' which is a more discriminative parameter instead of diuretic response or differential renal function estimation in determination of necessity of surgery $[3,4]$.

We retrospectively evaluated the patients without diuretic response in diuretic renal scintigraphy with additional analysis of tissue tracer transit. The aim of this study is to compare the results of the pediatric patients with follow-up or surgery results that do not have diuretic response in diuretic renal scintigraphy.

\section{Materials and Methods}

\section{Patients}

The subjects of this retrospective study were twenty nine pediatric patients (10 F, 19 M; mean: $4.4 \pm 3.96$ years old, range: 0 -15) without diuretic response estimated by diuretic renal scintigraphy. The patients were retrieved from the patients who were referred for dynamic renal scintigraphy between January 2009 and January 3013. After physical examination and routine laboratory analysis (including plasma urea, creatinine levels, and urine analysis and urine culture) baseline ultrasonographic assessment and voiding study were performed to all patients. All patients were referred for diuretic renal scintigraphy for evaluation of hydronephrosis. 


\section{Ultrasonography}

Ultrasonography examination of patients performed with $3.5 \mathrm{MHz}$ convex probe. Kidneys, ureters and bladder were visualized in transverse and longitudinal planes. Dilatation of pelvicalyceal system and ureter were recorded and the grade of hydronephrosis was determined for each kidney. Sonographic assessment of bladder included determination of wall thickness and capacity of bladder as well as presence of any abnormalities on ureterovesical junction.

\section{Scintigraphy}

Dynamic scintigraphy was performed after intravenous administration of Tc-99m MAG3 or Tc-99m DTPA (according to the body weight and adult dose of $3 \mathrm{mCi}$ for Tc-99m MAG3 and $10 \mathrm{mCi}$ for Tc-99m DTPA) with previous oral hydration (at least $500 \mathrm{ml}$ water/ fruit juice/milk intake or frequent breast feeding is recommended). Additionally $1 \mathrm{mg} / \mathrm{kg}$ intravenous furosemid was administered to all the patients at first minute of the study ( $\mathrm{F} 0$ protocol). The imaging was acquired in dynamic manner in supine position with flow phase (including first 30s images, $64 \times 64$ matrix, with 1.33 zoom in neonates) and total of $20 \mathrm{~min}$ acquisition time by SPECT gamma camera (GE Infinia 2, Israel) with parallel hole, high resolution low energy collimator. Spot images were also acquired after emptying the bladder. The diuretic response was considered according to these parameters: washout of the tracer from renal pelvis in post void images and increasing trend of the renogram curve after diuretic administration. The images were interpreted by an experienced nuclear medicine physician.

\section{Evaluation of tissue transit time (TTT)}

The TTT results were divided into two groups according to a previously described method [5]. The classification was based on these parameters:

\section{Timely TTT: physiological stasis.}

Delayed TTT: increase in paranchymal uptake in the delayed phase of study without or late clearance of the tracer to the pelvis without diuretic response.

\section{Surgery}

The patients whose pelvis AP diameter increases in USG follow-up and who became complicated with infection were referred for surgery. Pyeloplasty surgery was performed to eleven patients. The patients in the infantile age and with inconsistened imaging findings (for example present flow in the intravenous pyelography) were preferred to be included in the follow-up group.

The diuretic renography results and additional intravenous pyelography, voiding and ultrasonography results performed within one month were compared with control ultrasonography and/or diuretic renography results in $7.38 \pm 6.69$ month follow-up. Upgrade of the grade of hydronephrosis in the effected kidney in ultrasonograhy and/or estimated volume loss (exceeding 10\% relative uptake) or clinical additional problems (like infection, renal failure) are considered progressive disease. Significant decrease in the AP pelvis diameter in the ultrasonography and/or diuretic responsiveness in dynamic renal scintigraphy and/or disappearance of dilatation in the static renal scintigraphy considered as improvement.

\section{Results}

Fifteen of the patients were presented with left and fourteen with right hydronephrosis. Three patients had grade 1, eight had grade 2, fourteen had grade 3 and four patients had grade 4 hydronephrosis at the time of diagnosis according to the ultrasonography. The etiology of the patients was ureteropelvic junction obstruction in all. All of the patients were non responsive to diuretic administration in diuretic renography according to visual assessment of the scintigraphy images. Additional TTT analysis of the images revealed timely TTT in four patients in whole group and others had delayed TTT according to the criteria mentioned above.

Simultaneous intravenous pyelographies of 4 of the patients revealed present excretion to the ureter. 11 patients underwent surgical approaches (pyeloplasty) mean $4.2 \pm 4.1$ months after scintigraphy.

Among patients with surgical follow-up 11 (100\%) had recovery in the follow-up. In the follow-up group which consist of 18 patients 7 patients (39\%) had recovery, 5 had stabile disease and 6 had additional pathologies (one ureter dilatation, infection in three, one worsening of diuretic response, one volume loss) (Figures 1 and 2). Among those four patients with timely TTT all were in follow-up group and recovered spontaneously (Table 1).

\begin{tabular}{|l|l|l|}
\hline Characteristics & Surgery & Follow-up \\
\hline Gender & $8 \mathrm{M} / 3 \mathrm{~F}$ & $10 \mathrm{M} / 7 \mathrm{~F}$ \\
\hline Age & $5.3 \pm 4.3$ years & $3.7 \pm 3.7$ years \\
\hline Laterality & $6 \mathrm{R} / 5 \mathrm{~L}$ & $8 \mathrm{R} / 9 \mathrm{~L}$ \\
\hline Grade 2 & $\mathrm{N}=4$ & $\mathrm{~N}=10$ \\
\hline Grade 3 & $\mathrm{N}=2$ & $\mathrm{~N}=5$ \\
\hline Grade $\geq 4$ & $\mathrm{~N}=5$ & $\mathrm{~N}=2$ \\
\hline Follow-up period & $8.9 \pm 6.9$ months & $6.3 \pm 6.5$ months \\
\hline TTT (Tissue transit time) & 11 delayed & 4 timely 13 delayed \\
\hline
\end{tabular}

Table 1: The results of the patients in follow-up and surgery groups.

\section{Discussion}

Although the pathologic determination of UPJ is not certain the most common pathology in childhood hydronephrosis is UPJ obstruction. This entity is more common in boys with left predominance and especially in the infantile period [5]. There are several explanations for the UPJ obstructions among them most important theory is the discontinuity of smooth muscle fibers with hyperthyrophy and increased collagen formation with discontinuity of nerves at the portion with stenosis [6].Additionally there are some explanations including mechanical obstruction of vessels to the ureter [5]. These mechanical compression mechanisms can be realized with the increased frequency of obstruction in the horseshoe kidney patients.

The symptomatology of the patients varies and may include abdominal pain, hematuria and urinary tract infections. Most of the patients are asymptomatic and recently most of the patients are identified by antenatal ultrasound imaging. Ultrasound imaging is the most common procedure for both identification of the obstruction, 


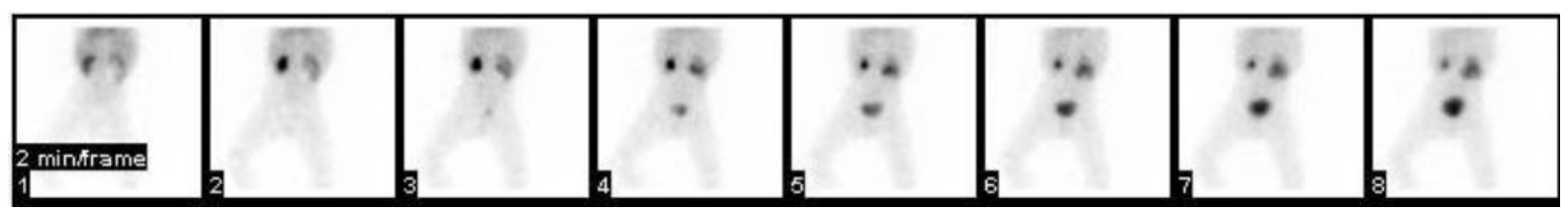

Figure 1: Dynamic Tc-99m MAG3 scintigraphy images of a patient without diuretic response and delayed TTT in the right kidney.

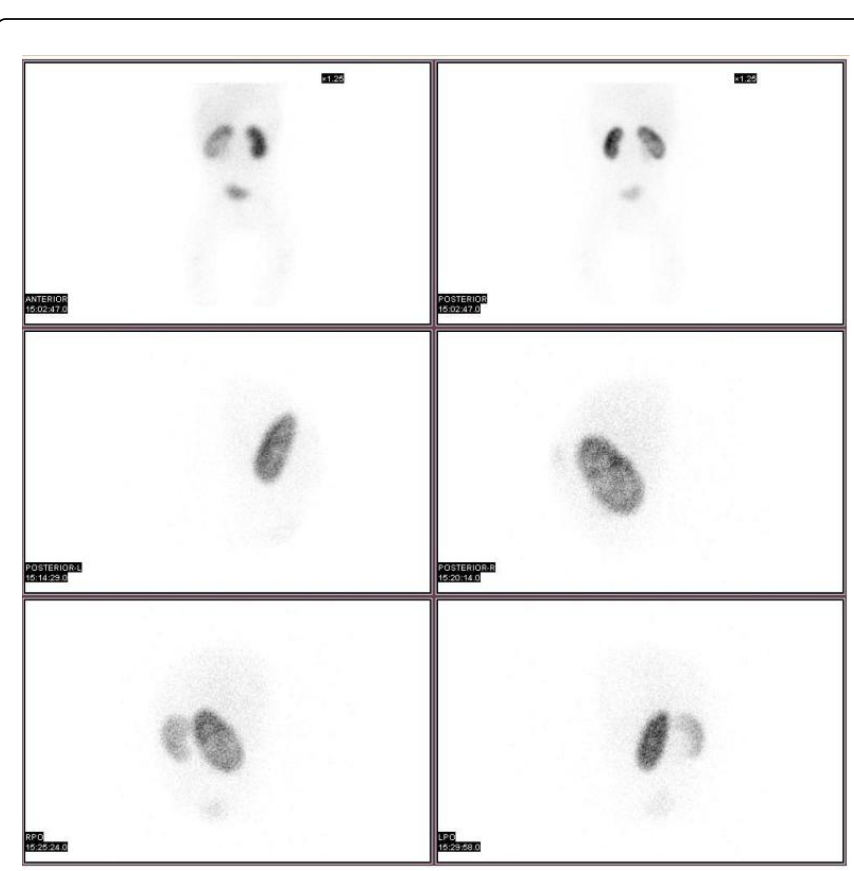

Figure 2: Follow-up static Tc-99m DMSA scintigraphy images reveal improvement of kidney function in the medical follow-up.

hydronephrosis or existing additional urinary system pathologies. Additionally postnatal ultrasound imaging reveals disappearance of antenatal hydronephrosis in $20 \%$ of the cases [7]. The imaging modalities employed in the pediatric radiourology are classified in a recent report (8). The report indicated that in the imaging algorithm of hydroneprosis voiding cystourethrography (VCUG) should be included particularly if the hydronephrosis is bilateral for determination of posterior uretral valve. In patients with UPJ obstruction surgery is not recommended in the first month of life and follow-up with imaging modalities should be preferred. The indication for the surgery include increasing pelvicalyceal dilatation with narrowing of the paranchymal tissue, increased parachymal echogenicity and corticomedullary differentiation. Additionally compensators hypertrophy of contralateral kidney, decrease in split renal function and loss of drainage function are considered surgical indications according to this report [8].

Recently MR urography has been introduced in pediatric urology which achieved superior information regarding morphology with similar results in assessment of renal function without radiation exposure compared to radionuclide imaging in a recent study [9]. Additionally another comparative study has demonstrated the superiority of MR urography compared to intravenous pyelography
[10]. In another study by Little et al. the evaluation of surgical results has been documented more sensitively compared to radionuclide imaging by MR [11]. Additionally some researchers have introduced MR urography as a selective approach for the patients who might benefit from surgery [12]. However, MR urography is a novel method for pediatric urology applications and requires a learning curve compared to radionuclide imaging methods. Additionally long imaging times with a noise acquisition requires sedation in most of the children which hampers the technique. Further studies and routine applications are needed in order to validate the method.

Diuretic renal scintigraphy is an essential part of examination of UPJ obstruction which provides prognostic information about the kidneys. Split renal function and detailed functional information including diuretic response could be obtained by dynamic renal imaging. However, there are important factors that may influence diagnostic accuracy of this modality. These are inadequate patient hydration and suprarenal function (falsely increased estimation of the relative renal function in the hydronephrotic kidney) due to the increased size of the kidney with hydronephrosis. There are additional recommended manevours like a post void image in sitting position and catheterization of bladder in order to avoid the effect of full bladder to the collecting system. The indications for important obstruction are $\mathrm{T} 1 / 2>20 \mathrm{~min}$, relative renal function of $<40 \%$ and complete loss of diuretic response [5]. There are also more recent evaluation methods as an adjunct of renography which are tissue transit time (TTT). The delay in TTT is a result of compromised filtration fraction (FF) and reduction of glomerular filtration rate (GFR) [4]. Schlottman et al. have indicated that a prolonged TTT requires surgical correction in patients with obstruction whose results have shown that significant functional decline can be predicted by delayed TTT in patients with obstruction [4]. Britton et al. have suggested combined use of diuretic response and TTT parameters in the evaluation of obstruction [13]. Additionally Schlottmann and Murer et al. have documented their findings with histologic changes in obstruction $[4,14]$.

The management of UPJ obstruction includes medical management in most of the patients especially without any symptom or loss of relative renal function. Most of the researchers believe that UPJ obstruction is a benign condition and thus can be observed without surgery for up to two years $[15,16]$. However, there are also reports that have indicated progressive renal function loss in the $15-33 \%$ of the patients with asymptomatic hydronephrosis among whom only half of them improved after further pyeloplasty approach [15].

In the patients with UPJ obstruction the most common surgical procedure is pyeloplasty. The procedure yield high therapeutic success in most of the series exceeding 95\% [17]. The reoperation rate in these patients is low like in $2-5 \%$ of the cases [5]. However, the relative renal function under $10-15 \%$ indicates nephrectomy [18]. Additionally there are several endourological and laparoscopic methods which yield success rates as high as open pyeloplasty surgery with higher patient 
comfort. All the patients in our study group underwent open pyeloplasty surgery.

In our patient group the patients with surgical follow-up results revealed excellent follow-up results. However, in the medical follow-up recovery was restricted to the $39 \%$ of the patients with worsening in the important percentage of the patients $(30 \%, n=6)$ which was a significant finding. Among our patients eight patients were in infant age (0-1 years old) and among infantile patients except one patient all were in medical follow-up group and recovered in the follow-up. Thus it might be concluded that in infantile period surgery might be postponed to elder ages despite lack of diuretic response. Additionally in our group among the four patients with existing excretion in ureter despite lack of diuretic response one improved after surgery, one spontaneously, one patient experienced stabile disease and one additional infection. In the four patients with timely TTT recovery was observed in the medical follow-up. Thus TTT analysis might reveal further prognostic information in the patients without diuretic response. Further studies are strongly recommended in prospective large series of the patients without diuretic response with analysis of TTT results

Limitations of our study include retrospective manner of the study, the decision of the final results based on ultrasonography in some patients (lack of follow-up scintigraphy of some patients) and two different agents to conclude diuretic response (Tc-99m MAG3 and Tc-99m DTPA).

According to the results of this study in patients without diuretic response in scintigraphy even without conclusive morphological results, surgery is a more appropriate management approach although the follow-up period of some patients were insufficient to conclude exact disease course. Evaluation of TTT in conjunction with diuretic response in scintigraphy might reveal better information.

\section{References}

1. Kiratli PO, Orhan D, Gedik GK, Tekgul S (2008) Relation between radionuclide imaging and pathologic findings of ureteropelvic junction obstruction in neonatal hydronephrosis. Scand J Urol Nephrol 42: 249-256.

2. Sepilveda JC, Salas JR, Mane S, Tarrado X, Morales L (2004) Evolution of pre and postoperative renographic parameters in pyeloreteral junction obstruction syndrome. Cir Pediatr 17: 179-184.

3. Scholotmann A, Clorius JH, Clorius SN (2009) Diuretic renography in hydronephrosis: Renal tissue tracer transit predicts funtional course and thereby need for surgery. Eur J Nucl Med Mol Imaging 36: 1665-1673.
4. Scholotmann A, Clorius JH, Rohrschneider WK, Clorius SN, Amelung F, et al. (2008) Diuretic Renography in hydronephrosis: Delayed Tissue Transit Accompanies Both Functional Decline and Tissue Reorganization. J Nucl Med 49: 1196-1203.

5. Lee H, Han SW (2009) Ureteropelvic juntion obstruction: What we know and what we don't know. Korean J Uro 50: 423-431.

6. Hosgor M, Karaca I, Ulukus C, Ozer E, Ozkara E, et al. (2005) Structural changes of smooth musle in congenital ureteropelvic junction obstruction. J Pediatr Surg 40: 1632-1636.

7. Dejter SW, Gibbons MD (1989) The fate of infant kidneys wih fetal hydronephrosis but initially normal postnatal sonography. J Urol 142: 661-662.

8. Riccabona M, Avni FE, Blickman JG, Dacher JN, Darge K, et al. (2009) Imaging recommendations in paediatric uroradiology. Minutes of the ESPR uroradiology task force session on childhood obstructive uropathy, high-grade fetal hydronephrosis, childhood haematuria, and urolithiasis in childhood. ESPR Annual Congress, Edinburgh, UK, June 2008. Pediatr Radiol 39: 891-898.

9. Brayfield MRP, Kirsch AJ, Jones RA, Grattan-Smith JD (2003) A prospective study comparing ultrasound, nuclear scintigraphy and dynamic contrast enhanced magnetic resonance imaging in the evaluation of hydronephrosis. J Urol 170: 1330-1334.

10. Wille S, Knobloch RV, Klose KJ, Heidenreich A, Hofmann R (2003) Magnetic resonance urography in pediatric urology. Scand J Urol Nephrol 37: 16-21.

11. Little SB, Jones RA, Smith JDG (2008) Evaluation of UPJ obstruction before and after pyeloplasty using MR urography. Pediatr Radiol 38: 106-124.

12. Smith JDG, Little SB, Jones RA (2008) MR urography evaluation of obstructive uropathy. Pediatr Radiol 38: 49-69.

13. Britton KE, Nawaz MK, Whitfield HN, Nimmon CC, Carroll MJ, et al. (1987) Obstructive nephropathy:Comparison between parenchymal transit time index and frusemide diuresis. Br J Urol 59:127-132.

14. Murer L, Benetti E, Centi S, Vella MD, Artifoni L, et al. (2006) Clinical and molecular markers of chronic interstitial nephropathy in congenital unilateral ureteropelvic junction obstruction. J Urol 176: 2668-2673.

15. Onen A, Jayanthi VR, Koff SA (2002) Long-term follow-up of prenatally detected sever bilateral newborn hydronephrosis initially managed nonoperatively. J Urol 168: 1118-1120.

16. Koff SA, Campbell K (1992) Nonoperative management of unilateral neonatal hydronephrosis. J Urol 148: 525-531.

17. Glick PL, Harrison MR, Noall RA, Villa RL (1983) Correction of congenital hydronephrosis in utero III. Early mid-trimester ureteral obstruction produces renal dysplasia. J Pediatr Surg 18: 681-687.

18. Sutherland DE, Jarrett TW (2009) Surgical options in the management of ureteropelvic junction obstruction. Curr Uro Reports 10: 23-28. 